\title{
Incidence and predictors of kyphotic deformity following resection of cervical intradural tumors in adults: a population-based cohort study
}

\author{
Charles Tatter ${ }^{1,2}$ (D) Alexander Fletcher-Sandersjööö ${ }^{1,2} \cdot$ Oscar Persson ${ }^{1,2} \cdot$ Gustav Burström $^{1,2} \cdot$ Per Grane $^{3}$. \\ Erik Edström $^{1,2} \cdot$ Adrian Elmi-Terander $^{1,2}$
}

Received: 4 March 2020 / Accepted: 15 May 2020 / Published online: 16 June 2020

(C) The Author(s) 2020

\begin{abstract}
Background The first line of treatment for most cervical intradural tumors is surgical resection through laminotomy or laminectomy. This may cause a loss of posterior pulling force leading to kyphosis, which is associated with decreased functional outcome. However, the incidence and predictors of kyphosis in these patients are poorly understood.

Object To assess the incidence of posterior fixation (PF), as well as predictors of radiological kyphosis, following resection of cervical intradural tumors in adults.

Methods A population-based cohort study was conducted on adult patients who underwent intradural tumor resection via cervical laminectomy with or without laminoplasty between 2005 and 2017. Primary outcome was kyphosis requiring PF. Secondary outcome was radiological kyphotic increase, measured by the change in the $\mathrm{C} 2-\mathrm{C} 7 \mathrm{Cobb}$ angle between pre- and postoperative magnetic resonance images.

Results Eighty-four patients were included. Twenty-four percent of the tumors were intramedullary, and the most common diagnosis was meningioma. The mean laminectomy range was 2.4 levels, and laminoplasty was performed in $40 \%$ of cases. No prophylactic PF was performed. During a mean follow-up of 4.4 years, two patients $(2.4 \%)$ required delayed PF. The mean radiological kyphotic increase after surgery was $3.0^{\circ}$, which was significantly associated with laminectomy of $\mathrm{C} 2$ and $\mathrm{C} 3$. Of these, $\mathrm{C} 3$ laminectomy demonstrated independent risk association.

Conclusions There was a low incidence of delayed PF following cervical intradural tumor resection, supporting the practice of not performing prophylactic PF. Kyphotic increase was associated with C2 and C3 laminectomy, which could help identify atrisk patients were targeted follow-up is indicated.
\end{abstract}

Keywords Cervical spine $\cdot$ Kyphosis $\cdot$ Laminectomy $\cdot$ Laminoplasty $\cdot$ Intradural tumor $\cdot$ Spinal cord tumor

This article is part of the Topical Collection on Spine - Other

Electronic supplementary material The online version of this article (https://doi.org/10.1007/s00701-020-04416-4) contains supplementary material, which is available to authorized users.

Charles Tatter

charles.tatter88@gmail.com

1 Department of Neurosurgery, Karolinska University Hospital, Elite Hotel Carolina, 4th floor, 17176 Stockholm, Sweden

2 Department of Clinical Neuroscience, Karolinska Institutet, Stockholm, Sweden

3 Department of Neuroradiology, Karolinska University Hospital, Stockholm, Sweden

\section{Introduction}

Spinal intradural tumors are benign or malignant growths that arise in or around the spinal cord. They account for $2-4 \%$ of all primary central nervous system tumors [1] and can give rise to symptoms such as sensorimotor disturbances and urorectal dysfunction [2]. The first line of treatment for most cervical intradural tumors is surgical resection [3] where the spinal canal is usually accessed via a posterior approach that includes detachment of paraspinal muscles and removal of the spinous process and lamina as well as associated ligaments including the interspinous ligament and ligamentum flavum $[4,5]$. As a consequence, extensor muscle force may be reduced. Experimental models and finite element studies have shown that the majority of the axial load transmission in the 
cervical spine goes through the posterior columns [6]. Loss of extensor force may therefore lead to a forward shift of the axial load transmission, predisposing the patient to development of cervical kyphosis [7, 8]. Highlighting this, several authors have reported a high incidence of postoperative kyphosis after intradural tumor surgery [9]. This has been shown to impair functional outcome $[5,10,11]$ and may also require later stabilization with posterior fixation $[12,13]$. Despite this, predictors of kyphotic deformity and incidence of posterior fixation following resection of cervical intradural tumors are poorly defined.

The aim of this study was to assess the incidence and predictors of long-term kyphosis following resection of cervical intradural tumors, evaluating the need for delayed posterior fixation surgery and describing situations where prophylactic stabilization may be indicated.

\section{Methods}

\section{Patient selection and study setting}

All adult patients ( $\geq 15$ years) who underwent cervical laminectomy (where lamina was removed and not reinstated) or laminectomy with laminoplasty (where lamina was removed but reinstated using microplates and screws) and intradural tumor resection between 2005 and 2017 were eligible for inclusion. Exclusion criteria were previous cervical laminectomy and simultaneous laminectomy of the thoracic spine; the latter was to avoid potential confounding effects of laminectomy at the cervicothoracic junction in accordance with previous literature [14]. The study hospital is a publicly funded and owned tertiary care center serving a region of roughly 2 million inhabitants and is the only neurosurgical center in the region. Patients were identified using the surgical management software Orbit (EVRY Healthcare Systems, Solna, Sweden) and were, as part of a previous study, crossreferenced with the national cancer registry to ensure that all eligible patients were included [2]. Medical records and imaging data from digital hospital charts were retrospectively reviewed using the health record software TakeCare (CompuGroup Medical Sweden AB, Farsta, Sweden). The study was approved by the Regional Ethical Review Board (Dnr: 2016/1708-31/4) who waived the need for informed consent.

\section{Surgical technique and follow-up}

The operations were performed by either of three senior consultant neurosurgeons as the primary attending. With the patient in prone position, a posterior midline approach was performed. Laminectomy was then conducted using an ultrasonic bone scalpel (from 2012 to 2017) (Misonix Inc., Farmingdale,
NY, USA) or a high-speed diamond bit drill and Kerrison rongeur (between 2005 and 2011). Under the microscope, the dura was incised, and the arachnoid was dissected sharply, allowing exposure of the tumor. For extramedullary tumors, the cranial and caudal poles were identified, and the tumor was dissected from surrounding structures. For intramedullary tumors, a midline myelotomy was performed using a diamond knife, and the tumor was then dissected sharply or removed using an ultrasonic aspirator (Sonopet, Stryker, USA). When visual gross total resection was achieved, the myelotomy was closed and sutured [2]. Watertight dural closure was performed in all cases. When laminoplasty was performed, the laminae were repositioned using microplates (CMF Medicon Surgical Inc., Jacksonville, FL, USA). The soft tissue layers were then sutured individually to close the wound. Following surgery, all patients were subjected to long-term clinical and radiological follow-up in accordance with local protocols, which differed slightly depending on tumor type and histopathological grade. Those who presented with pain or neurological deficit due to kyphosis were considered for posterior fixation surgery.

\section{Radiological assessment}

Calculation of cervical lordosis and kyphotic increase was performed on midline sagittal views of supine magnetic resonance images (MRI) using PACS (Picture Archiving and Communication System, IDS7, Sectra AB, Linköping, Sweden). Cervical lordosis was measured with the C2-C7 Cobb angle [11], which measures the angle between the lower endplates of C2 and C7 (Fig. 1). Kyphotic increase was defined as the difference in $\mathrm{C} 2-\mathrm{C} 7 \mathrm{Cobb}$ angle between the preoperative and long-term follow-up MRI ("delta-cobb"). For patients that required a delayed stabilization procedure, the last MRI prior to surgery was used.

\section{Statistics}

For descriptive purposes, continuous data are presented as mean (standard deviation), and categorical data, as numbers (proportion). Shapiro-Wilk test was used to test for normality of distribution. Two statistical models were used. First, McNemar's test (dichotomized data) and Wilcoxon signedrank test (continuous data) were used to test for consistent differences between pre- and postoperative functional status. Secondly, a univariate linear regression was conducted to assess predictors of radiological kyphotic increase. For this, delta-cobb was used as the continuous dependent variable where an increase correlated to a larger degree of kyphotic increase. Factors that showed a trend toward significance in the univariate analysis $(p<0.1)$ were then entered into a stepdown multivariable linear regression analysis to determine independent risk factors. In the step-down model, the least 
Fig. 1 Measurement of a $12^{\circ} \mathrm{C} 2$ $\mathrm{C} 7 \mathrm{Cobb}$ angle from a sagittal T2weighted magnetic resonance image

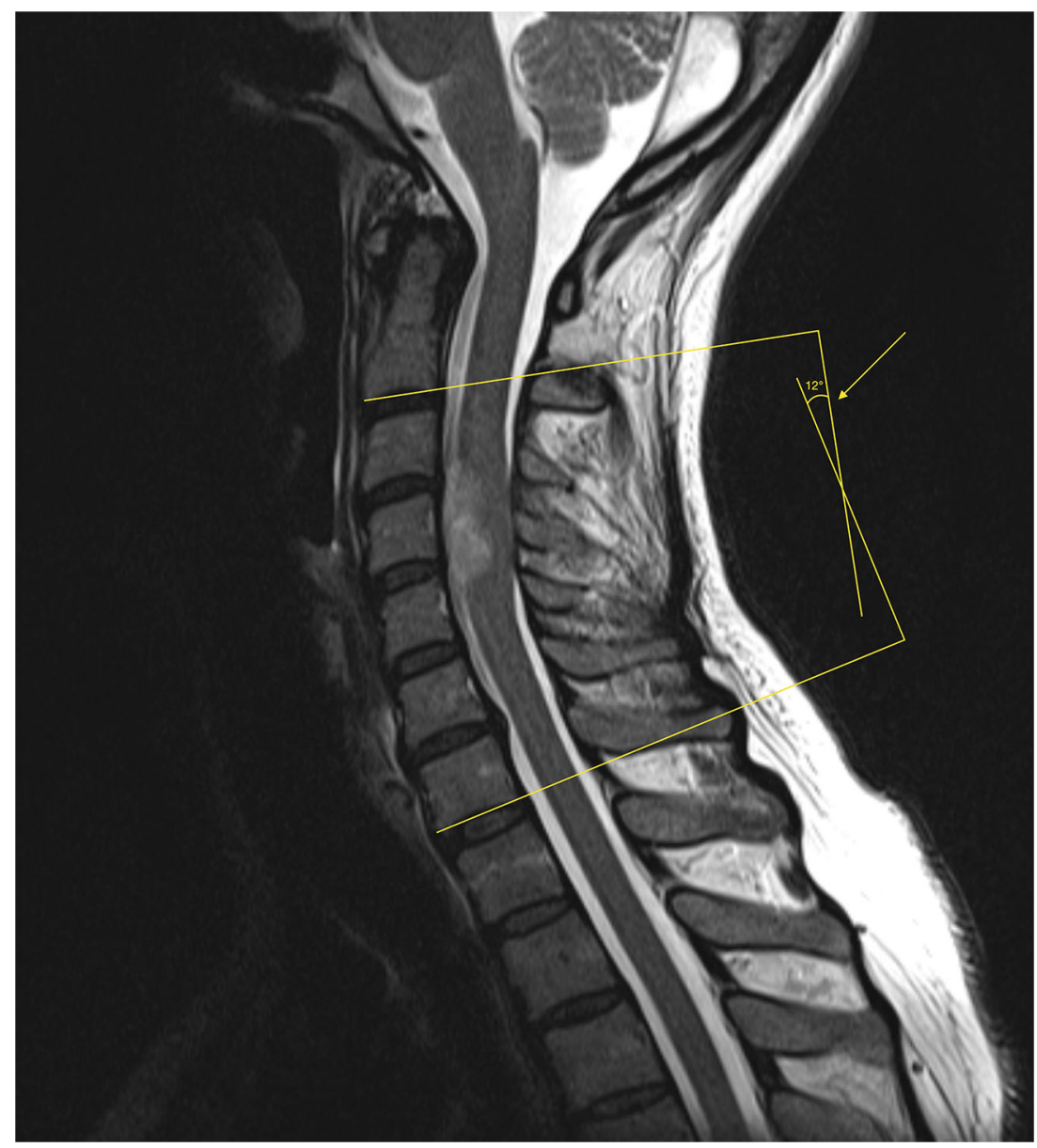

significant variable was sequentially eliminated until only significant variables remained. Listwise deletion was used to handle missing data. The statistical significance level was set to $p<0.05$. All statistical analyses were conducted using SPSS (IBM Corp. IBM SPSS Statistics, Version 25.0, 2017. Armonk, NY: IBM Corp.).

\section{Results}

\section{Participants and descriptive data}

A total of 112 patients met the inclusion criteria. Among these, 5 patients were excluded due to previous cervical laminectomy, 13 were excluded due to simultaneous laminectomy of the thoracic spine, and 10 were lost to follow-up. Thus, 84 patients were included in the study and constitute the study cohort. Thirty-seven (44\%) of the patients were male, and the mean age was 52 years. The mean preoperative $\mathrm{C} 2-\mathrm{C} 7 \mathrm{Cobb}$ angle was $14 \pm 15^{\circ}$ lordosis. The mean preoperative modified McCormick scale was $1.8 \pm 0.7$, and the most common symptoms were pain $(n=50,60 \%)$ and sensory deficit $(n=44,52 \%)$. Six patients $(7 \%)$ had neurofibromatosis (Table 1).

\section{Treatment}

The mean tumor extent was $2.1 \pm 1.0$ levels, and $26(31 \%)$ were dumbbell shaped. Twenty $(24 \%)$ of the tumors were intramedullary. The mean laminectomy range was $2.4 \pm 1.0$ levels. Laminoplasty was performed in 34 cases (40\%), and facet joint resection, in $5(6.0 \%)$. Prophylactic posterior fixation was not performed in any patient (Table 1). The most common histological diagnosis was meningioma $(n=26$, $31 \%)$, followed by schwannoma $(n=25,30 \%)$ and ependymoma $(n=11,13 \%)$ (Table 2$)$.

\section{Outcome data: clinical parameters}

The mean follow-up time was $4.4 \pm 3.3$ years. During this time, two patients $(2.4 \%)$ underwent delayed posterior fixation due to kyphosis. Tumor growth or recurrence occurred in eight $(10 \%)$ patients, of whom two underwent renewed tumor resection (both schwannomas) and one received adjuvant radiotherapy (a suspected malignant intramedullary tumor with inconclusive histology) (Table 1).

Compared to the preoperative status, surgery was associated with a significant decrease in modified McCormick scale ( $p$ 
Table 1 Baseline characteristics and treatment outcomes

\begin{tabular}{|c|c|}
\hline Variable & Value $(n=84)$ \\
\hline \multicolumn{2}{|l|}{ Baseline data } \\
\hline Male sex & $37(44 \%)$ \\
\hline Age (years) & $52 \pm 15$ \\
\hline Prior cervical radiation & $1(1.2 \%)$ \\
\hline Neurofibromatosis & $6(7 \%)$ \\
\hline Body mass index (BMI) & $26 \pm 4.6$ \\
\hline $\mathrm{C} 2-\mathrm{C} 7$ angle & $14 \pm 15^{\circ}$ lordosis \\
\hline \multicolumn{2}{|l|}{ Symptoms } \\
\hline Modified McCormick scale & $1.8 \pm 0.7$ \\
\hline Motor deficit & $38(45 \%)$ \\
\hline Sensory deficit & $44(52 \%)$ \\
\hline Pain & $50(60 \%)$ \\
\hline \multicolumn{2}{|l|}{ Treatment data } \\
\hline Intramedullary tumor & $20(24 \%)$ \\
\hline Dumbbell tumor & $26(31 \%)$ \\
\hline Tumor extent (levels) & $2.1 \pm 1.0$ \\
\hline \multicolumn{2}{|l|}{ Method } \\
\hline Laminectomy & $50(60 \%)$ \\
\hline Laminoplasty & $34(40 \%)$ \\
\hline Laminectomy extent (levels) & $2.4 \pm 1.0$ \\
\hline Including C1 & $23(27 \%)$ \\
\hline Including C2 & $25(30 \%)$ \\
\hline Including C3 & $36(43 \%)$ \\
\hline Including C4 & $36(43 \%)$ \\
\hline Including C5 & $34(40 \%)$ \\
\hline Including C6 & $35(42 \%)$ \\
\hline Including C7 & $18(21 \%)$ \\
\hline Joint resection & $5(6.0 \%)$ \\
\hline Prophylactic posterior fixation & $0(0 \%)$ \\
\hline Adjuvant radiation & $1(1.2 \%)$ \\
\hline \multicolumn{2}{|l|}{ Outcome data } \\
\hline Follow-up time (years) & $4.4 \pm 3.3$ \\
\hline Modified McCormick scale & $1.6 \pm 0.7$ \\
\hline Cervical tumor growth or recurrence & $8(10 \%)$ \\
\hline $\mathrm{C} 2-\mathrm{C} 7$ angle & $11 \pm 18^{\circ}$ lordosis \\
\hline Delta-cobb & $3.0 \pm 12^{\circ}$ kyphotic increase \\
\hline Cervical reoperation & $5(6.0 \%)$ \\
\hline Renewed tumor resection & $2(2.4 \%)$ \\
\hline Wound revision (infection) & $1(1.2 \%)$ \\
\hline Posterior fixation & $2(2.4 \%)$ \\
\hline Time to posterior fixation (years) & 1.0 and 1.2 \\
\hline
\end{tabular}

Data presented as mean (standard deviation) or number (proportion)

$=0.003)$, motor deficit $(p<0.001)$, and pain $(p<0.001)$ (Supplementary table 1). Three patients who did not undergo posterior fixation developed neck pain in the absence of significant kyphotic increase and were managed conservatively.
Table 2 Pathology report

\begin{tabular}{ll}
\hline Diagnosis & Value $(n=84)$ \\
\hline Ependymoma & 11 \\
Hemangioblastoma & 4 \\
Meningioma & 26 \\
Neurofibroma & 9 \\
Schwannoma & 25 \\
Other & 11 \\
Intradural chordoma & 1 \\
Hemangiopericytoma & 1 \\
Histology inconclusive & 2 \\
Intramedullary lipoma & 2 \\
Neurilemmoma & 1 \\
Neurothekeoma & 1 \\
Dermoid & 1 \\
\hline
\end{tabular}

\section{Outcome data: kyphosis}

The mean kyphotic increase (delta-cobb) was $3.0 \pm 12^{\circ}$ (Table 1). Some degree of kyphotic increase (delta-cobb > $0^{\circ}$ ) was seen in $47(56 \%)$ patients (Fig. 2). For these patients, the mean kyphotic increase was $10 \pm 11^{\circ}$. For the eight patients with tumor growth or recurrence, the mean kyphotic increase was $2.5 \pm 9.7^{\circ}$. Laminectomy at higher cervical levels (C1-C4) was more frequently associated with a kyphotic increase while laminectomy of lower levels (C5-C7) was more often associated with a lordotic change (Fig. 3).

In the univariate linear regression model predicting kyphotic increase, laminectomy of C2 $\left(p=0.026, R^{2}=0.049\right)$ and laminectomy of C3 ( $\left.p=0.003, R^{2}=0.100\right)$ were identified as significant risk factors (Table 3 ). In the multivariable model, laminectomy of $\mathrm{C} 3$ demonstrated independent risk association $(p=0.004)$. Laminectomy, as opposed to laminoplasty, was not significantly associated with an increased risk for postoperative kyphosis (Table 4).

\section{Subgroup analysis: posterior fixation}

Two patients required delayed posterior fixation due to kyphosis. The first patient was a 38 -year-old male with an intramedullary ependymoma who underwent tumor resection and laminectomy of $\mathrm{C} 3-\mathrm{C} 4$. He had a preoperative $\mathrm{C} 2-\mathrm{C} 7$ Cobb angle of $28^{\circ}$ lordosis. Following surgery, he gradually developed cervicalgia and restrained cervical mobility, and MRI revealed a kyphotic increase (delta-cobb) of $65^{\circ}$ (Fig. 4). He underwent posterior fixation of $\mathrm{C} 2-\mathrm{C} 513$ months after initial tumor resection, with complete symptom resolution. The second patient was a 21-year-old female with a neurofibroma who underwent tumor resection and laminoplasty of $\mathrm{C} 1-\mathrm{C} 3$. She had a preoperative $\mathrm{C} 2-\mathrm{C} 7 \mathrm{Cobb}$ angle of $10^{\circ}$ kyphosis. Following surgery, she developed cervicalgia, and 


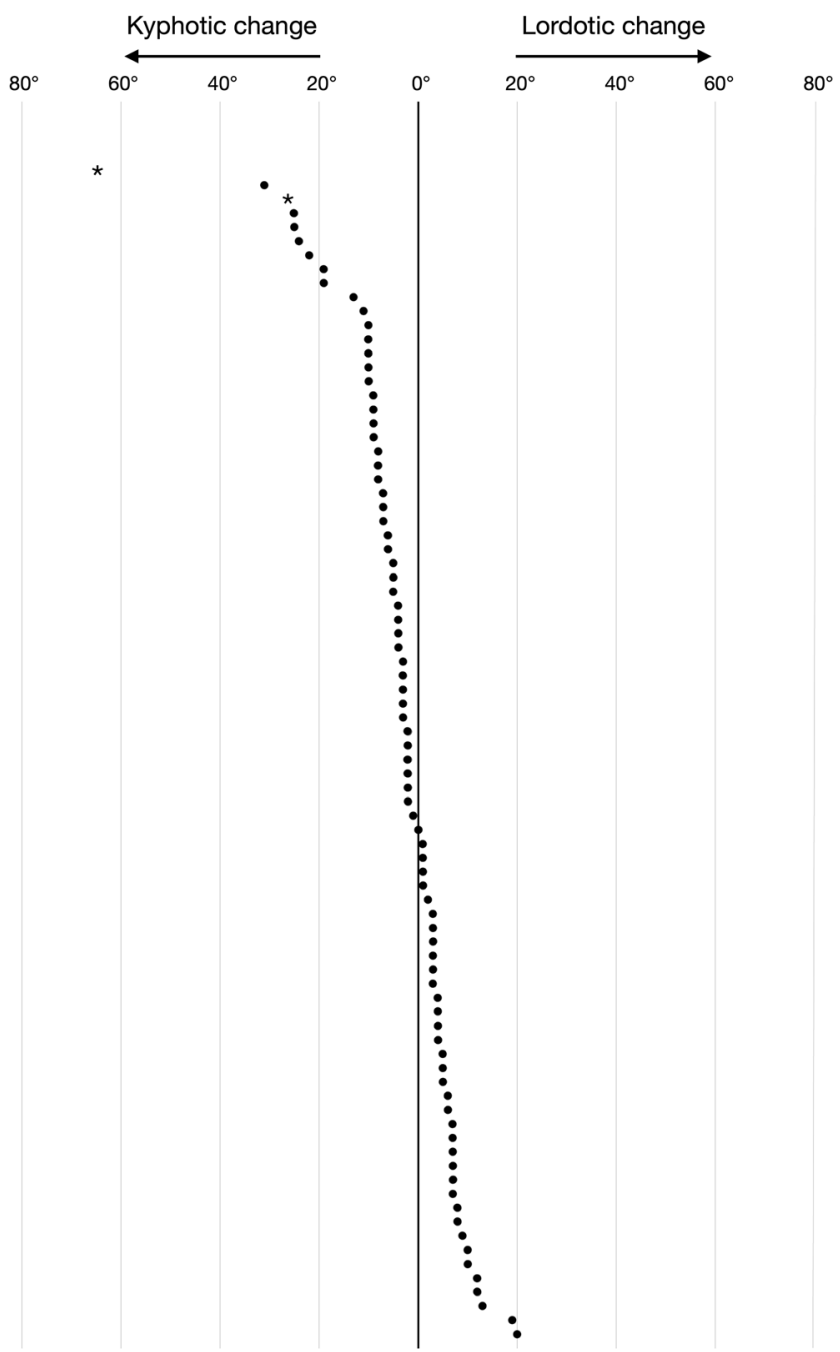

Fig. 2 Plot point graph, with each dot representing an individual patient, showing delta-cobb following laminectomy and intradural tumor resection for our cohort. The stars (full width asterisks) mark the two patients who underwent delayed posterior fixation due to symptomatic kyphosis

MRI revealed a kyphotic increase of $26^{\circ}$ (Fig. 5). For this, she underwent posterior fixation of $\mathrm{C} 2-\mathrm{C} 515$ months after initial tumor resection, with satisfactory outcome.

\section{Discussion}

The aim of this study was to assess the incidence of posterior fixation following resection of cervical intradural tumors, as well as predictors of radiological kyphotic increase. To the best of our knowledge, this is the largest study of its kind and contributes new findings that are important for patient management and future study design.

The mean preoperative $\mathrm{C} 2-\mathrm{C} 7 \mathrm{Cobb}$ angle was $14^{\circ}$ lordosis, which is considered normal according to a recent metanalysis of cervical lordosis in asymptomatic individuals [15]. During a mean follow-up time of 4.4 years, two (2.4\%) patients required a delayed posterior fixation. This incidence is lower compared to previous studies of cervical intradural tumors treated with laminectomy and tumor resection. In a study of 34 patients, Katsumi et al. reported that $9 \%$ required a posterior fixation within an undefined follow-up time [16]. In another study of 45 adult patients with cervical intradural tumors, of whom 13 underwent prophylactic fusion, 5 (16\%) of the remaining patients also required a delayed posterior fixation within a minimum follow-up time of 24 months [14]. It should be noted that both studies reported a larger laminectomy range than ours, with Sciubba et al. reporting a mean of 2.6 levels and Katsumi et al. reporting a mean of 3.2 levels (as compared to our mean of 2.4 levels). Moreover, we performed laminoplasty in $40 \%$ of cases as compared to Sciubba et al. who performed laminoplasty in $19 \%$ and Katsumi et al. who did not perform laminoplasty at all [16]. Thus, we report a $2.4 \%$ incidence of delayed posterior fixation following initial intradural tumor resection, which compares favorably to the existing literature and might be due to shorter laminectomy range and a higher degree of laminoplasty.

We found a mean kyphotic increase (delta-cobb) of $3.0^{\circ}$ and that $56 \%$ of patients showed some form of kyphotic increase (delta-cobb $>0^{\circ}$ ). Generally, we found that our cohort showed a normal distribution around zero with a few outliers where there was a large kyphotic increase (Fig. 2). We believe this highlights the fact that most patients do not run a risk of kyphosis but that there is a subset of at-risk patients that warrant early identification. Alluding to this, laminectomy of $\mathrm{C} 2$ and $\mathrm{C} 3$ was identified as a significant risk factor for kyphotic increase. This is supported by two previous studies that found intradural tumor resection and laminectomy of $\mathrm{C} 2$ to be associated with upper-level cervical kyphosis [17] and cervical instability [16]. Further highlighting the clinical significance of these results, the two patients who required a delayed posterior fixation in our cohort had undergone laminectomies including $\mathrm{C} 2$ and/or $\mathrm{C} 3$. In contrast, laminectomy of lower levels (C5-C7) was more often associated with a lordotic change (Fig. 3). This finding has previously been observed in studies of spinal deformity following surgery for spinal cord tumors $[17,18]$. The reason behind this may be explained by the findings in a finite element study in which Saito and colleagues demonstrated that the primary cause of postlaminectomy deformity was removal of the spinous processes and the posterior ligaments, causing the originally uniformly distributed stress to be transferred to the facets at the levels of laminectomy. In the post-laminectomy model, they asserted that the gravitational center of the head determined whether the deformity would develop as a kyphosis or increasing lordosis. In the model of upper cervical laminectomy, tensile stress was observed in the posterior direction causing increased pressure on the anterior part of the vertebral bodies and kyphosis. Conversely, a more lordotic pattern developed as the loading point was shifted in the posterior direction, as 
Fig. 3 Box plots showing deltacobb, following laminectomy and intradural tumor resection, depending on the level of laminectomy. $p$ values are from a univariate linear regression model using delta-cobb as the dependent variable and each level of laminectomy as the explanatory variable

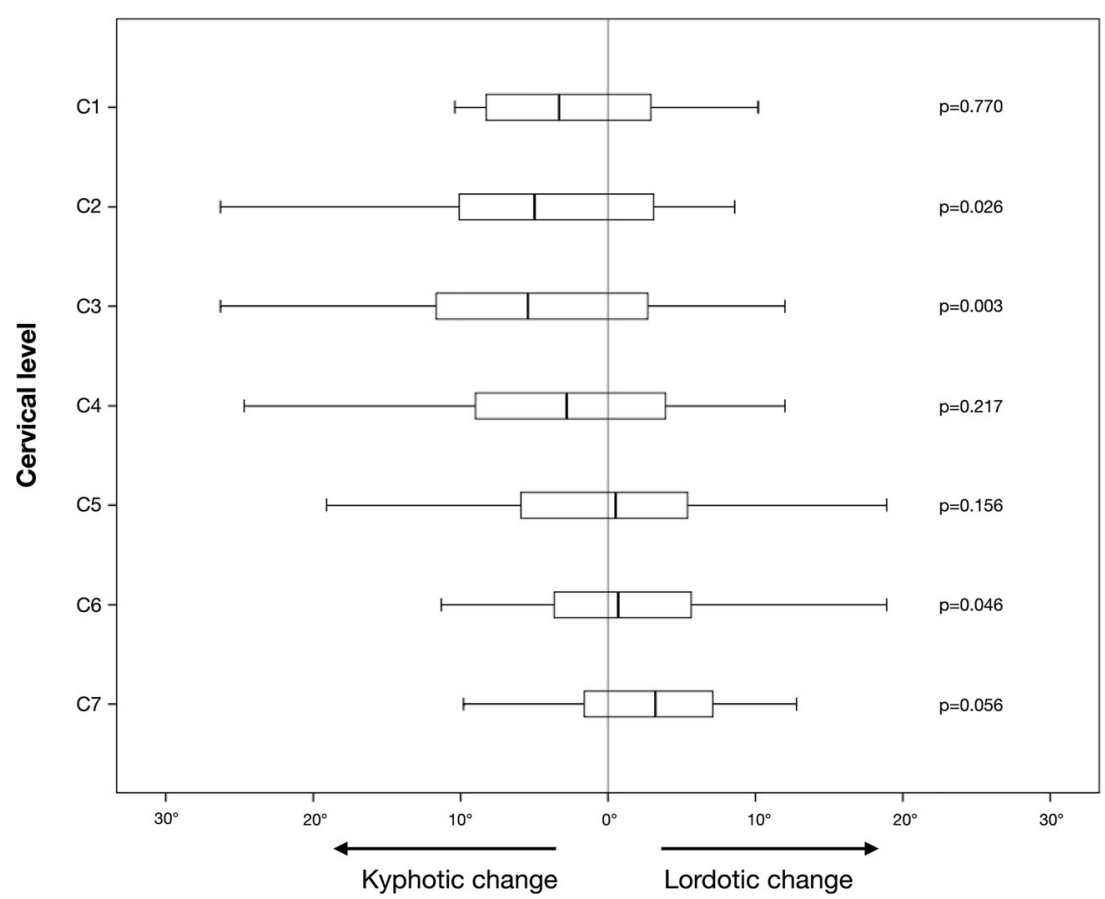

was the case for laminectomy at the lower cervical spine [19]. This explains why removal of the C7 lamina may result in lordosis of the cervical spine when measured using the $\mathrm{C} 2-$ C7 angle.

While both $\mathrm{C} 2$ and $\mathrm{C} 3$ were identified as predictors of postoperative kyphosis in the univariate analysis, C3 was the

Table 3 Predictors of increased kyphosis: univariate regression analysis

\begin{tabular}{ll}
\hline Variable & Univariate $p$ value \\
\hline Age & 0.067 \\
Male sex & 0.962 \\
Preoperative modified McCormick scale & 0.345 \\
Intramedullary tumor & 0.544 \\
Dumbbell tumor & 0.861 \\
Preoperative C2-C7 angle & 0.377 \\
Body mass index (BMI) & 0.080 \\
Gross total resection & 0.682 \\
Tumor extent & 0.791 \\
Laminectomy range (count) & 0.445 \\
Laminectomy including C1 & 0.770 \\
Laminectomy including C2 & 0.026 \\
Laminectomy including C3 & 0.003 \\
Laminectomy including C4 & 0.217 \\
Laminectomy (i.e., not laminoplasty) & 0.618 \\
Joint resection & 0.761
\end{tabular}

Italic text in the $p$ value column indicates a statistically significant correlation $(p<0.05)$ only one that showed independent risk association in our multivariable analysis. A possible explanation for this may be a bias where $\mathrm{C} 2$ laminectomy is avoided if not centered over the tumor and therefore essential to the surgery. In these cases, the adjacent $\mathrm{C} 3$ lamina will most often also be removed resulting in a material with very few cases of $\mathrm{C} 2$ laminectomy without C3. In our cohort with $25 \mathrm{C} 2$ laminectomies, only 1 was an isolated $\mathrm{C} 2$ laminectomy, and 9 were $\mathrm{C} 1-\mathrm{C} 2$ laminectomies. Thus, the remaining $60 \%(n=15)$ of $\mathrm{C} 2$ laminectomies were combined with a $\mathrm{C} 3$ laminectomy. Furthermore, while the spinous process and muscle attachments of $\mathrm{C} 3$ in itself are usually small, surgical access to the $\mathrm{C} 3$ lamina often requires detaching at least the inferior parts of the muscle insertions on C2. Several studies have emphasized the importance of the extensor muscle force on sagittal balance and that their detachment from C2 causes instability [16, 20-22]. Thus, in line with the proposed mechanism of relative extensor muscle weakness, this detachment of muscles from $\mathrm{C} 2$ may suffice in placing the patient at risk for development of cervical kyphosis [23].

In two previous studies of cervical intradural tumor resection, age at operation, preoperative spinal curvature, $\geq 3$-level cervical laminectomy, $\geq 4$-level cervical laminectomy, and destruction of facet joints were identified as predictors of cervical instability [16] or instability requiring fusion [14]. These were not identified as risk factors in our study. One reason behind this could be the difference in laminectomy range and use of laminoplasty, as described above. It could also be due to a difference in outcome variable. For example, while we analyzed risk factors of radiological kyphosis as a continuous 
Table 4 Independent predictors of postoperative kyphosis. Final results from the step-down multivariable logistic regression analysis

\begin{tabular}{llll}
\hline & Univariate $p$ value & $R^{2}$ & Multivariable $p$ value \\
\hline $\begin{array}{l}\text { Included variable } \\
\text { Laminectomy including C3 }\end{array}$ & 0.003 & 0.100 & 0.004 \\
Excluded variables & & & \\
Laminectomy including C2 & 0.026 & 0.059 & 0.084 \\
Body mass index (BMI) & 0.080 & 0.037 & 0.090 \\
Age & 0.067 & 0.040 & 0.195 \\
\hline
\end{tabular}

Italic text indicates a statistically significant correlation $(p<0.05)$
Fig. 4 Pre- (a) and postoperative (b) magnetic resonance image showing kyphosis following cervical laminectomy

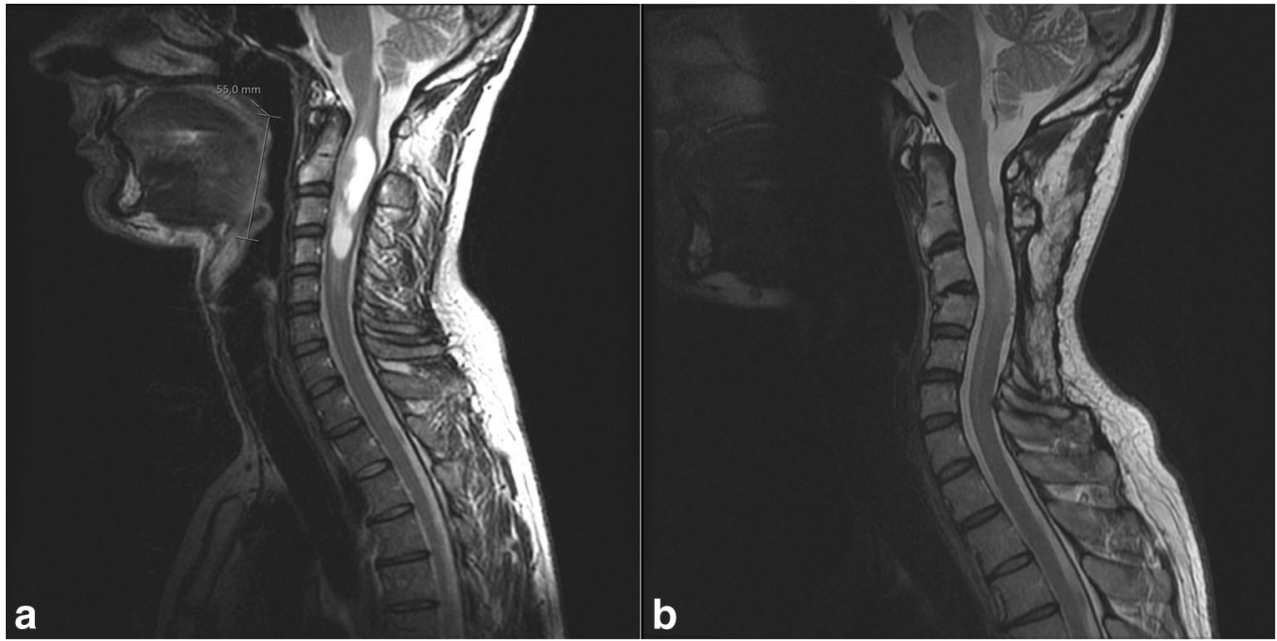

variable, Sciubba et al. analyzed predictors of kyphotic deformity requiring surgical stabilization [14]. This was not possible in our study due to the low incidence of posterior fixation.

We did not find that intramedullary tumor localization increases the risk for kyphosis. Of note, the mean kyphotic increase (delta-cobb) for intramedullary tumors was $4.4^{\circ}$ as compared to $2.6^{\circ}$ for the remaining tumors. Moreover, intramedullary tumors underwent a mean laminectomy range of 3.2 levels as compared to 2.2 levels in the remaining cohort.
Thus, it is possible that the regression analysis was underpowered to show a statistically significant difference between intra- and extramedullary tumors.

We did not find that laminoplasty decreased the risk for kyphosis. While there may be a theorized decreased risk for iatrogenic deformity, the literature has yet to establish conclusive efficacy of laminoplasty over laminectomy in preventing spinal deformity following intradural tumor resection as well as degenerative spinal
Fig. 5 Pre- (a) and postoperative (b) magnetic resonance image showing kyphosis following cervical laminectomy

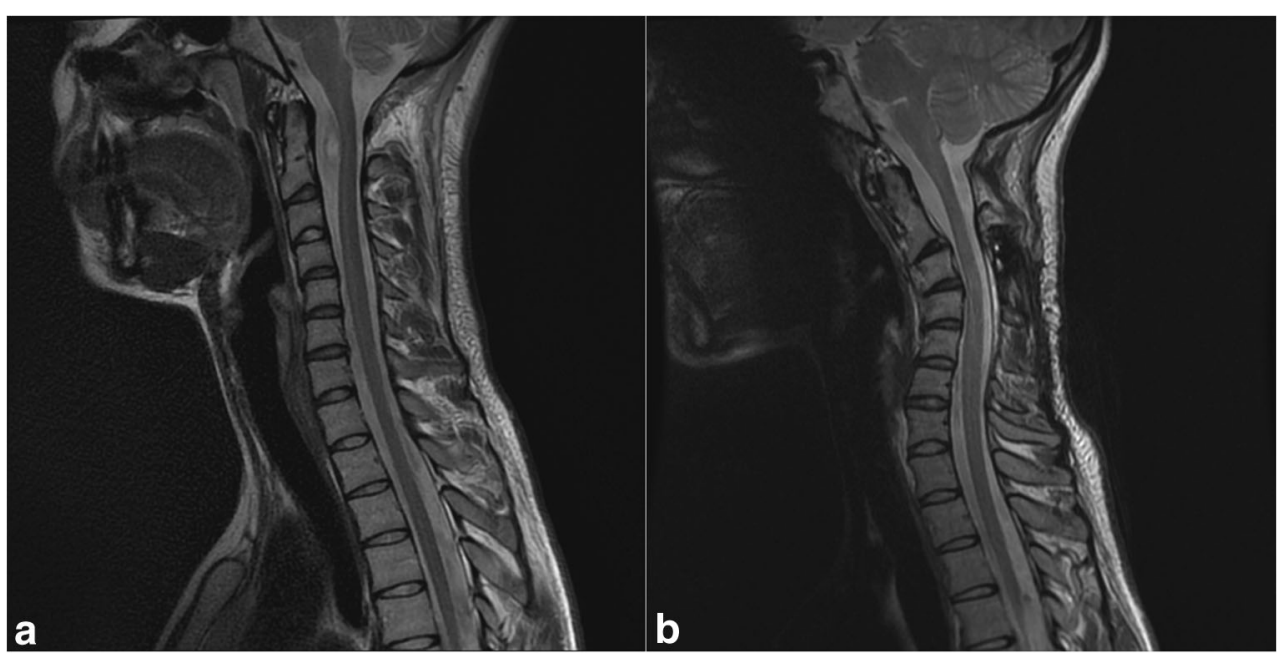


disorders $[5,18,24]$. Thus, our result is in accordance with the literature.

\section{Limitations}

There is no golden standard for measuring cervical sagittal malalignment. We, and many others [11], used the $\mathrm{C} 2-$ $\mathrm{C} 7 \mathrm{Cobb}$ angle as we believe it to be a reliable quantification of overall global cervical alignment that does not overlook distal junctional kyphosis [25]. However, other measurements of cervical sagittal malalignment exist, for example T1 slope, sagittal vertical axis, chin-brow vertical angle, and Cobb angle with the surgical area as end points $[11,15,26]$. Moreover, all measurements were performed on MRI obtained in a supine position, which may not be sensitive enough to visualize non-rigid kyphosis. MRI coil placement may also have influenced results. Furthermore, while some have dichotomized their results by employing cut-off values [5, 26], there is no definition of kyphotic change based on the C2-C7 Cobb angle. Lastly, radiologic evidence of kyphosis may not necessarily correlate to clinical outcome. For example, the patient in our cohort with the second highest kyphotic increase did not develop symptoms requiring posterior fixation (Fig. 2). Considering this, the most clinically relevant outcome measurement for future studies may be symptomatic kyphosis requiring stabilization.

\section{Conclusion}

The need for delayed posterior fixation in patients who underwent cervical intradural tumor resection was low, supporting the practice of not performing prophylactic posterior fixation. We found that kyphotic increase was associated with $\mathrm{C} 2$ and $\mathrm{C} 3$ laminectomy, which could help identify a subset of at-risk patients were targeted radiological and clinical follow-up is indicated.

Authors' contributions All authors participated in the study design, data interpretation, and revision and approval of the final manuscript. CT and AFS collected the data. AFS carried out the statistical analysis. CT and AFS created the draft of the manuscript. AET supervised the study.

Fundinglnformation Open Access funding provided by Karolinska Institute.

\section{Compliance with ethical standards}

Conflict of interest The authors declare that they have no conflict of interest.

Ethical approval All procedures performed in studies involving human participants were in accordance with ethical standards of the institutional and/or national research committee and with the
1964 Helsinki declaration and its later amendments or comparable ethical standards.

Informed consent The study was approved by Regional Ethical Review board in Stockholm, Sweden, who, in accordance with Swedish Law, waived the need for informed consent.

Open Access This article is licensed under a Creative Commons Attribution 4.0 International License, which permits use, sharing, adaptation, distribution and reproduction in any medium or format, as long as you give appropriate credit to the original author(s) and the source, provide a link to the Creative Commons licence, and indicate if changes were made. The images or other third party material in this article are included in the article's Creative Commons licence, unless indicated otherwise in a credit line to the material. If material is not included in the article's Creative Commons licence and your intended use is not permitted by statutory regulation or exceeds the permitted use, you will need to obtain permission directly from the copyright holder. To view a copy of this licence, visit http://creativecommons.org/licenses/by/4.0/.

\section{References}

1. Duong LM, McCarthy BJ, McLendon RE, Dolecek TA, Kruchko C, Douglas LL, Ajani UA (2012) Descriptive epidemiology of malignant and nonmalignant primary spinal cord, spinal meninges, and cauda equina tumors, United States, 2004-2007. Cancer 118(17):4220-4227

2. Persson O, Fletcher-Sandersjöö A, Burström G, Edström E, ElmiTerander A (2019) Surgical treatment of intra- and juxtamedullary spinal cord tumors: a population based observational cohort study. Front Neurol 10:814

3. Tobin MK, Geraghty JR, Engelhard HH, Linninger AA, Mehta AI (2015) Intramedullary spinal cord tumors: a review of current and future treatment strategies. Neurosurg Focus 39(2):E14

4. Krishnan Kutty R, Sreemathyamma SB, Sivanandapanicker JL, Asher P, Prabhakar RB, Peethambaran A Hemilaminectomy for spinal cord intradural tumors: an institutional experience. Asian J Neurosurg 13(3):760-765

5. McGirt MJ, Garcés-Ambrossi GL, Parker SL, Sciubba DM, Bydon A, Wolinksy J-P, Gokaslan ZL, Jallo G, Witham TF (2010) Shortterm progressive spinal deformity following laminoplasty versus laminectomy for resection of intradural spinal tumors: analysis of 238 patients. Neurosurgery 66(5):1005-1012

6. Pal GP, Sherk HH (1988) The vertical stability of the cervical spine. Spine (Phila Pa 1976) 13(5):447-449

7. Kode S, Kallemeyn NA, Smucker JD, Fredericks DC, Grosland NM (2014) The effect of multi-level laminoplasty and laminectomy on the biomechanics of the cervical spine: a finite element study. Iowa Orthop J 34:150-157

8. Yoganandan N, Kumaresan S, Pintar FA (2001) Biomechanics of the cervical spine. Part 2. Cervical spine soft tissue responses and biomechanical modeling. Clin Biomech 16(1):1-27

9. Asazuma T, Nakamura M, Matsumoto M, Chibo K, Toyama Y (2004) Postoperative changes of spinal curvature and range of motion in adult patients with cervical spinal cord tumors: analysis of 51 cases and review of the literature. J Spinal Disord Tech 17(3):178182

10. Albert TJ, Vacarro A (1998) Postlaminectomy kyphosis. Spine (Phila Pa 1976) 23(24):2738-2745

11. Scheer JK, Tang JA, Smith JS et al (2013) Cervical spine alignment, sagittal deformity, and clinical implications: a review. J Neurosurg Spine 19(2):141-159 
12. Fassett DR, Clark R, Brockmeyer DL, Schmidt MH (2006) Cervical spine deformity associated with resection of spinal cord tumors. Neurosurg Focus. https://doi.org/10.3171/foc.2006.20.2.3

13. McGirt MJ, Chaichana KL, Atiba A, Bydon A, Witham TF, Yao KC, Jallo GI (2008) Incidence of spinal deformity after resection of intramedullary spinal cord tumors in children who underwent laminectomy compared with laminoplasty. J Neurosurg Pediatr 1(1):57-62

14. Sciubba DM, Chaichana KL, Woodworth GF, McGirt MJ, Gokaslan ZL, Jallo GI (2008) Factors associated with cervical instability requiring fusion after cervical laminectomy for intradural tumor resection. J Neurosurg Spine 8(5):413-419

15. Guo G-M, Li J, Diao Q-X, Zhu T-H, Song Z-X, Guo Y-Y, Gao Y-Z (2018) Cervical lordosis in asymptomatic individuals: a meta-analysis. J Orthop Surg Res 13(1):147

16. Katsumi Y, Honma T, Nakamura T (1989) Analysis of cervical instability resulting from laminectomies for removal of spinal cord tumor. Spine (Phila Pa 1976) 14(11):1171-1176

17. Inoue A, Ikata T, Katoh S (1996) Spinal deformity following surgery for spinal cord tumors and tumorous lesions: analysis based on an assessment of the spinal functional curve. Spinal Cord 34(9): $536-542$

18. Nori S, Iwanami A, Yasuda A, et al (2017) Risk factor analysis of kyphotic malalignment after cervical intramedullary tumor resection in adults. J. Neurosurg. Spine. American Association of Neurological Surgeons, pp 518-527

19. Saito T, Yamamuro T, Shikata J, Oka M, Sutsumi S (1991) Analysis and prevention of spinal column deformity following cervical laminectomy I: pathogenetic analysis of postiaminectomy deformities. Spine (Phila Pa 1976) 16(5):494-502

20. Nolan JP, Sherk HH (1988) Biomechanical evaluation of the extensor musculature of the cervical spine. Spine (Phila Pa 1976) 13(1): 9-11

21. Shiraishi T, Yato Y (2002) New double-door laminoplasty procedure for the axis to preserve all muscular attachments to the spinous process: technical note. Neurosurg Focus. https://doi.org/10.3171/ foc.2002.12.1.10

22. Vasavada AN, Li S, Delp SL (1998) Influence of muscle morphometry and moment arms on the moment-generating capacity of human neck muscles. Spine (Phila Pa 1976) 23(4):412-422

23. Takeuchi K, Yokoyama T, Ono A, Numasawa T, Wada K, Kumagai G, Ito J, Ueyama K, Toh S (2007) Cervical range of motion and alignment after laminoplasty preserving or reattaching the semispinalis cervicis inserted into axis. J Spinal Disord Tech 20(8):571-576

24. Ratliff JK, Cooper PR (2003) Cervical laminoplasty: a critical review. J Neurosurg 98(3 SUPPL):230-238

25. Passias PG, Vasquez-Montes D, Poorman GW et al (2018) Predictive model for distal junctional kyphosis after cervical deformity surgery. Spine J 18(12):2187-2194

26. Knafo S, Court C, Parker F (2014) Predicting sagittal deformity after surgery for intramedullary tumors. J Neurosurg Spine 21(3): 342-347

Publisher's note Springer Nature remains neutral with regard to jurisdictional claims in published maps and institutional affiliations. 